\title{
Can a single primary care paramedic configuration safely transport low-acuity patients in air ambulances?
}

\author{
Homer Tien, MD, MSc* ${ }^{* \ddagger}$; Bruce Sawadsky, MD*; Michael Lewell, MD*; Sean Moore, MD*\$; \\ Michael Peddle, MD*; Alun Ackery, MD*; Brodie Nolan, MD*; Russell D. MacDonald, MD, MPH*
}

\section{ABSTRACT}

Objective: To determine if utilizing a single paramedic crew configuration is safe for transporting low acuity patients requiring only a primary care paramedic (PCP) level of care in Air Ambulances.

Methods: We studied single-PCP transports of low acuity patients done by contract air ambulance carriers, organized by Ornge (Ontario's Air Ambulance Service) for one year. We only included interfacility transports. We excluded all scene calls, and all Code 4 (emergent) calls. Our primary outcome was clinical deterioration during transport. We then asked a panel to analyze each case of deterioration to determine if a dual-PCP configuration might have reasonably prevented the deterioration or have better treated the deterioration, compared to a single-PCP configuration.

Results: In one year, contract carriers moved 3264 patients, who met inclusion criteria. $85 \%$ were from Northern Ontario. There were 21 cases of medical deterioration $(0.6 \% \pm 0.26 \%)$. Paper charts were found for 20 of these cases. Most were selflimited cases of pain or nausea. A small number of cases $(n=5)$ were cardiorespiratory decompensation. There was $100 \%$ consensus amongst the panel that all cases of clinical deterioration were not related to team size. There was also $100 \%$ consensus that a dual-PCP team would not have been better able to deal with the deterioration, compared to a single-PCP crew.

Conclusions: We found that using a single-PCP configuration for transporting low acuity patients is safe. This finding is particularly important for rural areas where air ambulance is the only means for accessibility to care and where staffing issues are magnified.

\section{RÉSUMÉ}

Objectif: L'étude visait à déterminer la sûreté du transport, en ambulance aérienne, de personnes atteintes d'affections bénignes, qui $\mathrm{n}^{\prime}$ ont besoin que de soins paramédicaux primaires et qui sont accompagnées d'un seul ambulancier paramédical.

Méthode: Nous avons étudié les transports de patients atteints d'affections bénignes, accompagnés d'un seul ambulancier paramédical en soins primaires (SP), effectués par des entreprises d'ambulance arérienne conventionnées, et organisés par Ornge (un fournisseur de services d'ambulance aérienne en Ontario) sur une période d'un an. Seuls ont été inclus les transports entre établissements, à l'exclusion des appels provenant des lieux d'accident et de ceux classés Code 4 (très urgents). Le principal critère d'évaluation consistait en la détérioration de l'état clinique durant le transport. Nous avons ensuite demandé à un groupe d'experts d'analyser tous les cas dans lesquels il y avait eu détérioration de l'état afin de déterminer si la présence d'une équipe formée de deux ambulanciers paramédicaux en SP aurait pu raisonnablement prévenir cette détérioration ou encore aurait pu mieux traiter celle-ci qu'une équipe formée d'un seul ambulancier paramédical en SP.

Résultats: Les entreprises conventionnées ont transporté, au cours de la période d'un an, 3264 patients dont l'état respectait les critères d'inclusion; $85 \%$ des appels provenaient du Nord de I'Ontario. II s'est produit une détérioration de l'état clinique dans 21 cas $(0,6 \% \pm 0,26 \%)$, et les dossiers de papier ont été retracés dans 20 d'entre eux. Il s'agissait, dans la plupart des cas, de douleurs ou de nausées spontanément résolutives. Dans un petit nombre de cas $(n=5)$, une décompensation cardiorespiratoire est survenue. De l'avis unanime du groupe d'experts, la détérioration de l'état clinique n'était, dans aucun des cas, liée à la grosseur de l'équipe. Il y avait également unanimité en ce qui concerne le traitement de la détérioration : une équipe composée de deux membres n'aurait pas mieux fait qu'une équipe composée d'un seul membre.

Conclusions: D'après les résultats de l'étude, le transport de personnes atteintes d'affections bénignes, accompagnées d'un seul ambulancier paramédical en SP est sûr. Les conclusions revêtent une importance particulière pour les

From the *Ornge, Mississauga, ON; †Division of General Surgery, Sunnybrook Health Sciences Centre, Toronto, ON; ¥Department of Surgery, University of Toronto, Toronto, ON; and the §Northern Ontario School of Medicine, Thunder Bay, ON.

Correspondence to: Dr. Homer Tien, Ornge, 5310 Explorer Drive, Mississauga, Ontario L4W 5H8; Email: htien@ornge.ca; Homer.tien@ sunnybrook.ca 
régions rurales où l'ambulance aérienne est le seul moyen $d^{\prime}$ accès aux soins et où la pénurie de personnel se fait sentir avec acuité.
Keywords: emergency medical services, prehospital care, air ambulances, patient safety, paramedics

\section{INTRODUCTION}

The development of regionalized health care in Canada has made it necessary to rely on ambulance programs for transport between facilities providing different levels of medical care. ${ }^{1}$ Most land and air ambulance programs in Canada require a two-person medical crew, and their regulations are based on literature suggesting that the dual provider configuration is safer. ${ }^{2-13}$ In general, however, the evidence for these recommendations is not extensive and somewhat dated. Moreover, one challenge of the method presented in existing literature is the heterogeneity of the types of providers studied (paramedics v. nurses v. physicians). ${ }^{2-13}$ Another major limitation is that patient safety was not explicitly defined or measured in these studies. The World Health Organization (WHO) Patient Safety Curriculum defines patient safety as "the reduction of risk of unnecessary harm associated with health care to an acceptable minimum." ${ }^{\text {"14 }}$ Measuring "the risk of unnecessary harm" requires a measurement of the error rate, the adverse effects of errors on patients, and some judgment regarding the notion of unnecessary risk and acceptable minimal level of risk. Previous studies measured intermediate outcomes such as time on scene or time to performance of procedures ${ }^{15-17}$; however, no studies, to the best of our knowledge, have examined the effect of provider team size on the explicit measurement of unnecessary risk of harm.

Another limitation of the literature is that previous studies focused primarily on transporting high-acuity critically ill patients between facilities in urban settings, or on rescuing, resuscitating, and transporting severely injured patients from the scene. ${ }^{15-17}$ There is no research on the optimal crew configuration for transporting low-acuity patients requiring a basic level of care (e.g., primary care paramedic [PCP]) from remote or underserviced communities to higher-level centres. In Ontario, many of our indigenous peoples live in such remote northern communities that require air ambulance to access primary level care. ${ }^{18}$ Furthermore, these communities struggle to recruit and retain qualified health care professionals including paramedics. ${ }^{19-21}$ Patients may access definitive care more quickly if a single provider was sent, versus waiting the additional time associated with coordinating two providers. Therefore, requiring a dual provider standard for crew configuration may adversely affect access to care for patients living in these remote communities. This standard may be too rigid if considering the problem of transporting low-acuity patients in remote communities.

We hypothesized that a single PCP configuration can safely transport low-acuity patients, if the level of care required during transport was deemed to be PCP. The objectives of this study were to: 1) describe the incidence of medical deterioration during the transport of low-acuity patients by a single PCP crew; and 2) identify whether deterioration was an unnecessary adverse effect of transport using a single PCP configuration. We did so by determining if the deterioration might have been prevented with the use of a dual PCP configuration and if the deterioration might have been significantly better treated by a dual PCP team versus a single PCP team.

\section{METHODS}

\section{Design}

This study involved a retrospective case series of patients transported by air ambulance using a single paramedic provider.

\section{Setting}

Ontario is the second largest province in Canada, with a landmass of 1.1 million $\mathrm{km}^{2}\left(424,000 \mathrm{mi}^{2}\right)$ in size. ${ }^{22}$ It is $90 \%$ wilderness with nearly one-sixth of the province covered by fresh water. Ornge is a non-profit company accountable to the Ontario government through a performance agreement and is responsible for all air ambulance operations in Ontario. This includes the contracting of flight service providers (service agreement carriers), medical oversight of all air paramedics, air dispatch, and the authorization of air and land ambulance transfers. 
In Northern Ontario, Ornge organizes and coordinates transport of low-acuity patients, mostly using contracted service agreement carriers. These carriers always use a crew configuration of a single PCP to service transports. Ornge reserves its own dedicated fleet of aircraft to service high-acuity calls (code 4: emergent and urgent), particularly those patients who require Advanced Care or Critical Care Paramedic level. Ornge uses a dual paramedic configuration for these calls.

\section{Study population}

We identified all PCP transports of low-acuity patients (codes 1-3: 1, deferrable; 2, scheduled; and 3, prompt) organized by Ornge and performed by a contracted service agreement carrier, from January 1, 2015, to December 31, 2015, using an electronic database. Only interfacility transports were included.

We excluded any patients for whom care was provided by higher-level paramedics (advanced care/critical care paramedics) and a sending facility medical escort (i.e., nurse and physician), and we excluded all calls deemed to be high acuity (code 4: emergent/urgent) and all scene calls.

\section{Data collection and management}

At Ornge, the PCPs from service agreement carrier groups chart their patient care using paper Ambulance Call Reports. Trained data abstractors at Ornge transcribe the information from the paper record into an electronic database. The resultant electronic database consists of both administrative and clinical data. All data are validated by range and logic checks and subjected to routine quality audits with high standards for data fidelity $(>95 \%$ verification against original paper records). Transcription occurs routinely, and thus, the abstractors were unaware of the research study or study question. However, the paper Ambulance Call Reports are also scanned and stored electronically at our organization. We obtained and accessed the scanned paper Ambulance Call Reports electronically for cases in which the paramedics recorded clinical deterioration.

\section{Definitions}

1. Low-acuity patients: these are patients determined to be non-emergent by the Ornge transport physician and predicted to require no active medical care during transport.

2. PCP level of care: in Ontario, PCPs provide the basic level of care to patients during transport. Their scope of practice includes providing select medications: acetaminophen, certain antibiotics, nitroglycerin, aspirin, epinephrine, salbutamol, ketorolac, naloxone, glucagon, dimenhydrinate, diphenhydramine, glucose, ibuprofen, sodium chloride, oxygen, and salbutamol. They can perform a limited number of procedures and controlled medical acts including defibrillation and obtaining 12-lead electrocardiograms (EKGs).

3. Patient safety: using the previously described WHO definition, we further defined "health care" studied as the choice of using a single PCP configuration versus a dual PCP configuration for transporting low-acuity PCP-level patients.

\section{Outcomes}

1. Clinical deterioration: any change in condition requiring active medical treatment by a paramedic during transport.

2. Unnecessary harm from single PCP configuration: potential differences in "harm" from choosing the single PCP configuration versus dual PCP configuration.

\section{Analytical approach}

We operationalized the measurement of this outcome in the following manner:

1. Clinical deterioration: Paramedics are required to document whether clinical deterioration occurred during transport. Under documentation rules, clinical deterioration is defined as any change in condition requiring active medical treatment by a paramedic. This finding was documented for every patient in the paper Ambulance Call Reports and was abstracted into an electronic database. We queried our electronic database for every study patient to determine if clinical deterioration occurred during transport. Unfortunately, medications administered during transport were not abstracted from the paper Ambulance Call Reports into the electronic database for service agreement transports.

2. "Unnecessary harm from single PCP configuration": We then determined if the documented medical deterioration constituted "unnecessary harm" from a single PCP configuration by reviewing the paper 
Ambulance Call Reportss for the study patients if deterioration was documented. We then prepared short, anonymized clinical summaries of each case in which deterioration occurred and asked each medical director of the Medical Advisory Committee (five members) at Ornge to make the following judgments: 1) Was the clinical deterioration observed believed to be secondary to the natural history of the patient's condition, or was the risk of this deterioration exacerbated by transport using the single PCP configuration? 2) Would the use of a dual PCP team have significantly increased the ability to treat the deterioration, as compared with that of a single PCP team? Consensus was deemed to have been reached if at least four of the five medical directors agreed on their answers to each question for each patient who experienced deterioration. Medical Advisory Committee members could respond, "unknown," to any questions on a patient. However, a minimum of four members was required to respond affirmatively or negatively to each question, or a teleconference would be convened to determine why the medical director was unable to make a judgment on a particular case. In such cases, consensus required four of the five Medical Advisory Committee members to agree on their answers.

Descriptive statistics were reported for all values. Means were reported with $95 \%$ confidence intervals (or \pm standard deviation) as appropriate. All data were analyzed using SAS software (v. 9.4). This study was approved by an institutional research ethics board. Individual patient consent to use patient information was not required by the research ethics board, as this was a retrospective study and personal identifiers were not used in this study. The authors assert that all procedures contributing to this work comply with the ethical standards of the relevant national and institutional committees on human experimentation and with the Helsinki Declaration of 1975, as revised in 2008.

\section{RESULTS}

During the year-long study period, 5,564 transports were performed by Scheduled Agreement (SA) carriers using a single PCP configuration. We eliminated those with medical escorts, leaving 3,467 single PCP transfers. We then eliminated all "Scene" calls, leaving 3,454 single PCP transfers. We removed all Code 4 calls, leaving 3,294 for further analysis. For 30 patients, we had no dispatch priority, and therefore, these were eliminated, leaving 3,264 patients for analysis.

Approximately, $85 \%$ of the calls occurred in Northern Ontario, and approximately $82 \%$ were deferrable or scheduled transports (Table 1). Many of the transports done by the single PCP configuration in the SA carriers were repatriations back to home health care facilities.

Of the 3,264 transports, paramedics recorded deterioration in 21 cases $(0.6 \%$ [95\% CI $0.34-0.86])$ (Table 2). The paper Ambulance Call Reportss for these 21 cases were retrieved electronically for further analysis. For one case, no paper Ambulance Call Report could be located. No deaths occurred while patients were in the care of the SA carrier paramedics. The major categories of deterioration were pain, nausea/ vomiting, and shortness of breath. Nausea was selflimited in all cases and controlled by dimenhydrinate. Five patients experienced cardiorespiratory deterioration during transport. However, two of these were palliative patients, and deterioration was expected. Only three patients of the 3,264 transports were at risk of a serious unforeseen, adverse outcome during transport; one patient (case 14) was short of breath before

\begin{tabular}{lc}
$\begin{array}{l}\text { Table 1. Baseline characteristics of single PCP transports } \\
\text { conducted by SA carriers }\end{array}$ \\
\hline Characteristic & Mean, count (\%) \\
\hline Age (years, mean \pm SD) & $57.1( \pm 23)$ \\
Gender (\% male) & $1668(51 \%)$ \\
Base & \\
Other & $4(0.12 \%)$ \\
Elliot Lake & $6(0.18 \%)$ \\
Moosonee & $313(9.6 \%)$ \\
Muskoka & $305(9.3 \%)$ \\
Sioux Lookout & $488(15.0 \%)$ \\
Thunder Bay & $1,440(44.1 \%)$ \\
Timmins & $510(15.6 \%)$ \\
Toronto & $198(6.1 \%)$ \\
Dispatch priority & \\
Level 1 (deferrable) & $1,612(49.4 \%)$ \\
Level 2 (scheduled) & $931(28.5 \%)$ \\
Level 3 (prompt) & $721(22.1 \%)$ \\
Reason for transport & \\
Repatriation & $1,399(42.9 \%)$ \\
Trauma & $195(6.0 \%)$ \\
Cardiovascular & $306(9.4 \%)$ \\
Gastrointestinal & $121(3.7 \%)$ \\
Neurological & $56(1.7 \%)$ \\
Other & $1187(36.4 \%)$ \\
\end{tabular}




\begin{tabular}{|c|c|c|c|c|c|}
\hline Case & Diagnosis & Deterioration & Description & $\begin{array}{l}\text { Natural } \\
\text { history }\end{array}$ & $\begin{array}{c}\text { No advantage } \\
\text { of dual PCP } \\
\text { team }\end{array}$ \\
\hline 1 & Repatriation & Pain, desaturation & $\begin{array}{l}\text { Ketorolac and oxygen provided; } \\
\text { symptoms improved }\end{array}$ & Agree* & Agree \\
\hline 2 & Repatriation & Post-op patient, complaint of pain & Unsure if improved & Agree & Agree \\
\hline 3 & Abdo pain & More pain & $\begin{array}{l}\text { Ketorolac provided; symptoms } \\
\text { improved }\end{array}$ & Agree & Agree \\
\hline 4 & Repatriation & Post-op patient with nausea, SOB, and abdo pain & $\begin{array}{l}\text { Oxygen provided; symptoms } \\
\text { improved }\end{array}$ & Agree & Agree \\
\hline 5 & Repatriation & $\begin{array}{l}\text { Patient with previous NSTEMI, DNR, with chest } \\
\text { pain }\end{array}$ & Nitroglycerin provided & Agree & Agree \\
\hline 6 & Repatriation & Post-op, with pain & Pain meds contraindicated & Agree & Agree \\
\hline 7 & Abdo pain & Pain & Ketorolac provided & Agree & Agree \\
\hline 8 & Fracture & Pain & Pain meds contraindicated & Agree & Agree \\
\hline 9 & Neuro consult & Pain & Unclear if improved & Agree & Agree \\
\hline 10 & Repatriation & Nausea & $\begin{array}{l}\text { Dimenhydrinate administered; } \\
\text { symptoms resolved }\end{array}$ & Agree & Agree \\
\hline 11 & Ankle fracture & Nausea & Unreadable & Agree & Agree \\
\hline 12 & Repatriation & Nausea & Resolve spontaneously & Agree & Agree \\
\hline 13 & Repatriation & Vomiting & Dimenhydrinate given & Agree & Agree \\
\hline 14 & Repatriation & $\begin{array}{l}\text { Patient with low oxygen sat prior to transport, with } \\
\text { SOB and desaturation }\end{array}$ & $\begin{array}{l}\text { Oxygen provided; symptoms } \\
\text { resolved }\end{array}$ & Agree & Agree \\
\hline 15 & Repatriation & Palliative care patient, confused with new SOB & $\begin{array}{l}\text { Oxygen provided; symptoms } \\
\text { resolved }\end{array}$ & Agree & Agree \\
\hline 16 & For imaging & Patient with DNR, with SOB and wheeze & Salbutamol, upgrade priority & Agree & Agree \\
\hline 17 & Repatriation & $\begin{array}{l}\text { Cardiac patient, with four new coronary stents and } \\
\text { arrhythmia (asymptomatic ventricular tachycardia) }\end{array}$ & $\begin{array}{l}\text { Oxygen provided, upgrade } \\
\text { priority }\end{array}$ & Agree & Consensus $^{\dagger}$ \\
\hline 18 & Mental health & Patient non-compliant & Police escort, no problems & Agree & Agree \\
\hline 19 & Repatriation & Elderly patient, acute delirium & Unclear what was done & Agree & Agree \\
\hline 20 & Repatriation & Unreadable & Unknown, transport done & Unknown & Unknown \\
\hline 21 & Repatriation & No deterioration identified, mental health patient & & Agree & Agree \\
\hline
\end{tabular}

transport and developed worsening shortness of breath during the flight. The second patient (case 5) developed worsening chest pain while being repatriated home after treatment for a non-ST-elevation myocardial infarction (NSTEMI). The last patient (case 17) had a revascularization procedure to improve coronary blood flow and developed an asymptomatic but worrisome arrhythmia (asymptomatic ventricular tachycardia) during the flight. Treatments administered were limited to supplemental oxygen, sublingual nitroglycerin, intramuscular ketorolac, and intramuscular dimenhydrinate.

On further analysis of the 20 cases for which a paper Ambulance Call Report could be located, the medical directors of the Medical Advisory Committee members were unanimous (100\% agreement) in judging that all cases of clinical deterioration were from the natural history of the underlying condition requiring transport and not from a single PCP configuration versus dual PCP configuration. Almost all cases of worsening pain were secondary to either progression of the underlying process or transport-induced pain, likely from movement. There was $100 \%$ agreement or consensus reached that a single PCP crew was just as capable of dealing with the clinical deterioration as a dual PCP configuration. One of the five medical directors on the Medical Advisory Committee thought that a dual PCP configuration would be better able to deal with asymptomatic arrhythmia (ventricular tachycardia), as compared with a single PCP crew. No teleconferences were required to reach consensus. 


\section{DISCUSSION}

We did a retrospective series of all low-acuity patients transported in Ontario by service agreement carriers organized by Ornge and demonstrated that the rate of clinical deterioration was low $(0.6 \%)$ for low-acuity patient transfers treated by a PCP. Of those cases that were reported to deteriorate, an expert panel felt a PCP could address the issues. Based on these results, we suggest that a single PCP configuration can safely transport low-acuity patients, if the level of care required during transport was appropriately deemed to be PCP. Almost one-half of these transports were repatriations to home hospitals, after initial transport to facilities providing a higher level of care. We found that almost all these transports occurred in Northern Ontario. Self-limited and predictable causes of deterioration included pain and nausea. More worrisome causes of deterioration were shortness of breath, chest pain, and a serious arrhythmia (ventricular tachycardia) after coronary revascularization.

Based on our findings, we feel that transports with a single PCP configuration for low-acuity patients are safe. On a structured chart review, none of the cases of clinical deterioration were felt to be secondary to the paramedic team size. All cases of deterioration were felt to be secondary to the natural history of the patients' original conditions. Further, our reviewers agreed or came to a consensus on all cases of clinical deterioration that a dual PCP team would not have been significantly better at treating the deterioration than a single PCP configuration.

However, our study raises the question of the need to review the level of care required for transporting all patients. Some qualitative comments made by our medical directors during their review of the cases of clinical deterioration (not presented) suggest that there is some ambiguity and disagreement in terms of which patients can be safely transported using a PCP level of care. Some of the medical directors disagreed with the initial decision of assigning the level of care of the transport to be "PCP" for certain calls. In part, based on the results of this study, Ornge no longer uses an algorithm for determining the level of care for low-acuity calls for SA carriers; instead, Ornge now mandates having a transport medicine physician screen all calls-even the perceived low-acuity calls for SA carriers-for level of care designation.

Dual PCP crew configuration remains common practice for high-acuity calls, particularly on-scene trauma calls and cardiac arrest calls. Rescuer fatigue and distraction are commonly cited as reasons why a single PCP configuration may negatively impact performance, as compared with a dual PCP standard. However, existing literature has not indicated the effect of paramedic crew size on cardiopulmonary resuscitation (CPR) performance..$^{25,26}$

\section{The risk of harm during transport}

This study adds to the available literature as it focuses on the safety of a group of patients during transport that has not been previously studied: low-acuity patients transported by a single-enquiring PCP level of care. In a study by Singh et al. ${ }^{22}$ of a medical air-transport service in Ontario, approximately $15 \%$ of all transports identified between January 1, 2004, and May 31, 2006 (7,685 out of 49,986), were accompanied by PCP crews only. However, no information was provided on crew configurations (single PCP v. dual PCP) or patient outcomes. The focus of the study by Singh et al. ${ }^{22}$ was on transports requiring either advanced care or critical care level paramedics. Of these 19,228 transports, Singh et al. ${ }^{22}$ found that $12(0.1 \%$ of the cases) died inflight. This is comparable to the mortality rate of $0.04 \%$ demonstrated by a prior study of all patients transported by Ornge. ${ }^{23}$ Further, Singh et al. ${ }^{22}$ reported that critical events occurred inflight in $5.1 \%$ of all transports, or once per 12.6 hours of transit time. Critical events occurred in $3.9 \%$ of transports from non-acute care facilities, as compared with $5.1 \%$ of transports from acute care facilities and $6.7 \%$ for on-scene calls. However, as discussed previously, these figures pertain only to urgent, unscheduled transports and explicitly excluded low-risk transports that were accompanied by PCPs only.

\section{Jurisdictional scan of crew composition and size}

Current literature has focused on reporting the experiences of different regions with different crew compositions and sizes. Manitoba, another province in Canada, requires at least two of the following as part of their air ambulance team complement: a qualified physician, a registered nurse (RN), and/or a registered emergency medical technician (EMT; i.e., an advanced paramedic certified in advanced cardiac and trauma life support [ACLS/ATLS] skills). ${ }^{2}$ A 2010 study by the US Government Accountability Office noted that most air 
ambulances in the United States carry a pilot and a twoperson medical crew, which may include a physician, nurse, paramedic, EMT, or other medical personnel. ${ }^{3}$ A 2003 government report produced in Ireland discussed the results of a survey of 21 helicopter air ambulance operators internationally. ${ }^{4}$ The report noted that operational crews varied across jurisdictions in terms of level of medical expertise (physicians, nurses, and paramedics) within a multiple crew member configuration. Another survey of 120 aeromedical programs (119 US-based programs and one international program) revealed that only $3 \%$ of programs used singlemember medical crews, while $96 \%$ of helicopter ambulances and $97 \%$ of fixed-wing ambulances used two-person medical crews. ${ }^{5}$ The configurations for two-person medical crews for helicopter and fixed-wing air ambulances were: nurse/paramedic $(71 \%$ and $61 \%$, respectively); nurse/nurse ( $8 \%$ and $8 \%$, respectively); nurse/physician (3\% and 3\%, respectively); nurse/EMT ( $1 \%$ and $5 \%$, respectively); nurse/other (i.e., registered respiratory therapist) (10\% and $18 \%$, respectively); paramedic/paramedic (5\% and $0 \%$, respectively); and other ( $2 \%$ and $5 \%$, respectively). However, most of these programs staffed their vehicles to respond primarily to critically injured or ill patients.

\section{Research evidence on the efficacy and impact of crew composition and size}

Galvagno et al. ${ }^{9}$ reviewed literature on the effects of helicopter emergency medical service (HEMS) programs and noted that "any [beneficial] effect of HEMS is likely due to some combination of crew expertise, prehospital interventions, and timely access to a highlevel trauma centre." The identified literature regarding the impact of crew composition on patient outcomes is mixed and inconclusive. A 1987 randomized trial by Baxt et al. ${ }^{10}$ compared the outcome of traumatized patients treated either by physician-nurse or paramedicnurse crews. The study found that physician-staffed crews reduced the expected mortality rate by approximately $35 \%$, while the paramedic-staffed crew was not able to lower the predicted mortality rate. However, the 2010 US Government Accountability Office (GAO) report $^{3}$ on air ambulances noted that there was no consensus across seven identified studies on how the composition of the medical crew influences a patient's outcome. Lockey and Weller ${ }^{11}$ stated that "as with other areas of controversy in aeromedical practice there have been few good prospective studies to show the benefit of any particular combination of personnel."

There are even fewer studies that examine the effect of the paramedic team size on patient outcomes. A study by Cameron et al. $^{12}$ examined single-paramedic-staffed HEMS in Victoria, Australia, that responded to blunt trauma cases by transporting patients $(n=242)$ from an accident scene to a hospital. The study found that the survival rates of transported patients (14\% mortality) were not significantly different from those predicted by the Major Trauma Outcome Study methodology.

\section{LIMITATIONS}

A major limitation of this study is how we determined if a safe transport occurred. We used the occurrence of clinical deterioration as a marker of "unsafe transport." We performed an electronic query of our database to identify cases in which the paramedic identified a clinical deterioration during transport. Paramedics may have intentionally or unintentionally omitted cases in which deterioration occurred. Further, deterioration implies an actual clinical change in the patients' status. The concept of "patient safety" and "minimizing unnecessary risk of harm from health care to an acceptable level" also implies that reducing the risk of "near misses" is part of enhancing patient safety. Our study was not able to measure "near misses" and therefore likely underestimated the potential risks of "unsafe transport."

Moreover, the concept of minimizing unnecessary risk to an acceptable level requires judgment during chart review. Gilbert et al. ${ }^{24}$ document the limitations of chart review in emergency medicine research, without appropriate attention to the methodology. The conclusions from the implicit review of charts by multiple reviewers are often not reproducible, as inter-rater reliability can be poor. Reviews performed using explicit criteria demonstrate high inter-rater reliability but are insensitive to the nuances of care. In this study, we attempted to maximize inter-rater reliability while maintaining sensitivity to nuances of care with the use of a structured methodology of implicit review. However, limitations regarding inter-rater reliability and sensitivity to nuances of care remain.

One other major limitation is attribution bias. The Medical Advisory Committee at Ornge was used to determine the outcome: judging whether all cases of clinical deterioration were secondary to single PCP 
transport versus dual PCP transport. However, we thought the effect of this bias was minimal. The actual cases of clinical deterioration were identified by the paramedics involved, not by the Medical Advisory Committee. One last limitation is that there is no measure in this study regarding provider safety. A dual PCP configuration may be inherently safer than a single PCP configuration from a workplace occupational health and safety perspective. Future research could focus on occupational health and safety claims comparing a single PCP with a dual PCP configuration.

\section{CONCLUSIONS}

In this study, we demonstrated that the incidence of medical deterioration during the transport of low-acuity patients by a single PCP was low $(0.6 \%)$. In addition, our expert panel felt that all cases of clinical deterioration were a result of disease progression and that a dual PCP crew would have not been able to prevent the deterioration more than a single PCP crew. We also demonstrated that all cases of deterioration were related to the natural history of the condition. In conclusion, this study provides the first evidence that a single PCP configuration is safe for transporting low-acuity patients requiring a PCP level of care. This finding is particularly important for providing service to rural areas where air ambulance is the only means for accessing care and where staffing issues are magnified. Consideration should be made to better screen each call for the level of care to ensure that paramedics with a scope of practice capable of managing these patients should accompany these calls.

Competing interests: $\mathrm{HT}$ is a salaried employee of Ornge and $\mathrm{BS}, \mathrm{ML}, \mathrm{SM}, \mathrm{MP}, \mathrm{RM}$, and AA are paid contractors for Ornge.

\section{REFERENCES}

1. Robinson V, Goel V, Macdonald RD, Manuel D. Interfacility patient transfers in Ontario: Do you know what your local ambulance is being used for?. Healthc Policy 2009;4(3): 53-66.

2. Office of the Auditor General of Manitoba. Helicopter Ambulance Program; 2014. Available at: http://www.oag. mb.ca/wp-content/uploads/2014/03/Chapter-4-HelicopterAmbulance-Program-Web1.pdf (accessed February 14, 2016).

3. United States Government Accountability Office (GAO). Air Ambulance: Effects of Industry Changes on Services Are Unclear; 2010 Available at: http://www.gao.gov/assets/320/ 310527.pdf (accessed February 14, 2016).
4. Booz Allen Hamilton. Final Report: Feasibility Study on a Helicopter Emergency Medical Service (HEMS) for the Island of Ireland; 2003 Available at: http://health.gov.ie/wpcontent/uploads/2014/03/Feasibility-Study-on-a-HelicopterEmergency-Medical-Service-HEMS-for-the-Island-of-Ireland. pdf (accessed February 15, 2016).

5. Rau W2000. Medical Crew Survey. AirMed, 2000;6(5):17-22.

6. Woodward GE. American Academy of Pediatrics Section on Transport Medicine. Guidelines for air and ground transport of neonatal and pediatric patients, 3rd ed. Elk Grove Village, IL: American Academy of Pediatrics; 2006.

7. Mathison DJ, Berg E, Beaver M. Variations in Interfacility Transport: Approach to Call Intake, Team Composition, and Mode of Transport. Clin Pediatr Emerg Med 2013; 14(3):193-205.

8. Floccare DJ, Stuhlmiller DFE, Braithwaite SA, et al. Appropriate and safe utilization of helicopter emergency medical services: a joint position statement with resource document. Prehosp Emerg Care 2013;17(4):521-5.

9. Galvagno S, Thomas S, Baker S, et al. Helicopter emergency medical services for adults with major trauma (Protocol). Cochrane Database Syst Rev 2011;8:CD009228. doi:10.1002/14651858.CD009228.

10. Baxt WG, Moody P. The impact of a physician as part of the aeromedical prehospital team in patients with blunt trauma. 7AMA 1987;257(23):3246-50.

11. Lockey D, Weller R. Aeromedical evacuation of the trauma patient. Trauma 1999;1(1):12-22.

12. Cameron PA, Flett K, Kaan E, Atkin C, Dziukas L. Helicopter retrieval of primary trauma patients by a paramedic helicopter service. Aust N Z J Surg 1993;63(10):790-7.

13. Andruszkow H, Frink M, Zecky C, et al. Merits and capabilities of helicopter emergency medical service (HEMS) in traumatized patients. Technol Health Care 2012;20(5):435-44.

14. World Health Organization Patient Safety Curriculum. World Health Organization; 2011. Available at: http://apps. who.int/iris/bitstream/10665/44641/1/9789241501958_eng. pdf (accessed February 15, 2016).

15. Martin-Gill C, Guyette FX, Rittenberger JC. Effect of crew size on objective measures of resuscitation for out-of-hospital cardiac arrest. Prehosp Emerg Care 2010;14(2):229-34.

16. Bayley R, Weinger M, Meador S, Slovis C. Impact of ambulance crew configuration on simulated cardiac arrest resuscitation. Prehosp Emerg Care 2008;12(1):62-8.

17. Martin-Gill C, Guyette FX, Rittenberger JC. Effect of crew size on objective measures of resuscitation for out-of-hospital cardiac arrest. Prehosp Emerg Care 2010;14(2):229-34.

18. Glazier RH, Gozdyra P, Yeritsyan N. Geographic Access to Primary Care and Hospital Services for Rural and Northern Communities: Report to the Ontario Ministry of Health and Long-Term Care. Toronto: Institute for Clinical Evaluative Sciences; 2011.

19. Rourke J, Dewar D, Harris K, et al; Task Force of the Society of Rural Physicians of Canada. Strategies to increase the enrollment of students of rural origin in medical school: recommendations from the Society of Rural Physicians of Canada. CMAJ 2005;172:62-5.

20. Martel R. Rural medicine needs help. Can Fam Physician 1995;41:974-6. 
21. Coyte PC, Catz M, Stricker M. Distribution of physicians in Ontario. Where are there too few or too many family physicians and general practitioners? Can Fam Physician 1997;43:677-83.

22. Singh JM, MacDonald RD, Bronskill SE, et al. Incidence and predictors of critical events during urgent air-medical transport. CMA7 2009;181(9):579-84.

23. MacDonald RD, Banks BA, Morrison M. Epidemiology of adverse events in air medical transport. Acad Emerg Med 2008;15(10):923-31.
24. Gilbert EH, Lowenstein SR, Koziol-McLain J, Barta DC, Steiner J. Chart reviews in emergency medicine research: Where are the methods? Ann Emerg Med 1996;27(3): 305-8.

25. Bayley R, Weinger M, Meador S, Slovis C. Impact of ambulance crew configuration on simulated cardiac arrest resuscitation. Prehosp Emerg Care 2008;12(1):62-8.

26. Martin-Gill C, Guyette FX, Rittenberger JC. Effect of crew size on objective measures of resuscitation for out-of-hospital cardiac arrest. Prehosp Emerg Care 2010;14(2):229-34. 